patients with glandular fever almost invariably develop a rash if given ampicillin, ${ }^{2-5}$ and the same is true to a lesser extent for some other antibiotics.

A survey of the literature shows that there has been a particularly high incidence of rashes in patients treated with ampicillin for Salmonella infections. It has been postulated that some of the rashes may be produced by endotoxin released by rapid lysis of bacteria, though there is little evidence to support this. Many of these patients received high dosage, but we have been unable to show a significant relationship between dosage and incidence.

An intensive investigation is being undertaken in an attempt to provide information on many of the unexplained features of the rash associated with ampicillin therapy.I am, etc.,

E. T. KNudsen. Medical Director,
Beecham Research Laboratories.

Brentford, Middx.

REFERENCES

1 Stevenson, J., and Mandal, B., Brit. med. F., 2 Pullen, H., Wright, N., and Murdoch, J. M., Lancet, 1967, 2, 1176.

Pullen, H., Wright, N., and Murdoch, J. M.,

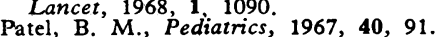

5 Gabbert, W. R., and Hopwood, Ann H., f. Ky med. Ass., 1968, 66, 967.

\section{Jakob-Creutzfeldt Disease}

SIR,-The statement in your leading article (1 March, p. 528) that the term "JakobCreutzfeldt disease" has been erroneously used by British neurologists and physicians for many years is simply not true. There is no evidence whatsoever that the cases so recognized by neurologists in Britain at least up to 1954 were not in general similar clinic ally and pathologically to the five patients described by Jakob. The fact that Spielmeyer, the renowned German neuropathologist, suggested the term " Jakob-Creutzfeldt disease" for what you wish to describe as " corticostriatonigral degeneration" you seem now to consider of no importance. It is surely folly to change without reason the name of a disease or syndrome, as it only confuses the student and hinders the advance of knowledge. The clinical condition which you label "Jakob-Creutzfeldt disease" and which has been transmitted to a chimpanzee was never described by either of these authors. It would be lamentable if our literature were allowed, in any degree, to become a mixture of unreality and makebelieve, in the justification of which it becomes necessary to discredit our distinguished predecessors.-I am, etc.,

\section{Maida Vale Hospital,
London W.}

S. NEVIN.

** It is true that W. Spielmeyer sugges ted that the term Jakob-Creutzfeldt disease should be applied to a neurological syndrome characterized by the slow development of Parkinsonian-like picture, often associated with dementia, signs of corticospinal tract degeneration, and amyotrophy in the limbs. More recently, however, many neurologists have come to the conclusion that the case which Jakob and Creutzfeldt originally described almost certainly represented a different diagnostic entity from that referred to by Spielmeyer. The general consensus of opinion among many neuropathologists in Britain and the majority in the U.S.A. is that the term Jakob-Creutzfeldt disease is more properly used to identify a syndrome characterized by rapidly progressive dementia developing in the presenium, often associated with myoclonus, and by a spongiform type of degeneration in the cerebral cortex seen at necropsy. The matter is still controversial, but majority opinion seems to be leaning towards the view expressed in our leading article rather than towards the more traditional British use of this diagnostic title as stressed by Dr. Nevin.-ED., B.M.F.

\section{Cerebral Malaria}

SIR,-I agree with Dr. P. W. Hutton (1 March, p. 578). I see no major difference between quinine and the 4-amino-quinolines (in the absence of parasite resistance) in the treatment of cerebral complications of falciparum malaria, so long as reasonable care is taken during administration to avoid the precipitation of medical shock.

Recent discussions (25 January, p. 256) indicate some misunderstanding of the processes involved in the development of coma, which is primarily due to incompetence of the cerebral circulation following leakage of protein and water through the endothelial walls of the small brain vessels. Quinine and chloroquine (and the corticosteroids for that matter) reverse this process, acting as anti-inflammatory agents; the restoration of the circulation leads to return of consciousness, often in a few hours. The antiparasitic activity of the drugs at this stage is not a factor in the immediate clinical response. We are lucky to have two such powerful schizonticides which are equally active antiinflammatory agents.

May I say how pleased I was to read Dr. Hutton's warning on falciparum malaria as it occurs in the United Kingdom. It is time the public and the profession appreciated the potential risks of overseas travel in this respect.-I am, etc., School of Tropical Medicine,
Liverpool 3 . BRIAN MAEgRaIth.

\section{New B.N.F}

SIR,-I should like to draw attention to what, in my view, is a possibly lethal error in the "Classified Notes for Prescribers" in the new edition of the British National Formulary. ${ }^{1}$ I refer to p. 76, where speaking about chlorpromazine it says, "It is, however, very effective in more severe agitated states, especially in the elderly in whom other drugs may cause confusion. Single injections ( $300 \mathrm{mg}$. or so) can be used to control acutely disturbed patients." It is not absolutely clear from the context whether this dosage is recommended only for the elderly, or for any acutely disturbed patients. However, none of my colleagues have eve used more than $150 \mathrm{mg}$. in a single injection, the usual maximum being $100 \mathrm{mg}$., whil the manufacturers, who admittedly tend to err on the conservative side, recommend only " $25-50 \mathrm{mg}$. in an injection."
Dr. P. S. Nemetz (18 January, p. 186) has recently drawn attention to the danger of injecting even $100 \mathrm{mg}$. of chlorpromazine in the elderly: "There is great potential for postural hypotension with brain softening, myocardial infarction, syncope with trauma, and even irreversible shock and death." $\mathrm{He}$ stresses that intramuscular injections have four or five times the potential of an oral preparation, and in my own experience it is rarely necessary to exceed a total oral daily dosage of $150 \mathrm{mg}$. in elderly patients. Intramuscular doses of $300 \mathrm{mg}$. would clearly be dangerous. - I am, etc.,

T. D. E. RICHARDSON.

Department of Psychological Medicine.

Midland Nerve Hospital,
Birmingham 15 .

REFERENCES

1 British National Formulary, 1968. British Medical Association and Pharmaceutical Society of cal Association and Phe

2 May and Baker, Largactil in Psychiatry, 1967, 7 th edition, p. 26. Dagenham. Essex, May
and Baker Ltd.

\section{B.N.F. Recommendations}

SIR,-The British National Formulary 1968 makes admirable recommendations about the abbreviations which should be used in prescribing. Perhaps a future addition would advise on the rationalization of the terms “b.d.," “t.d.s.," “t.i.d.," “q.d.s.," "q.i.d.," " nocte," and others which are commoniy used on prescription sheets, especially in hospitals.

A complete standardization of terminology in prescriptions should be useful for pharmacists, doctors, and nurses. In the interests of accuracy, simplicity, and safety in prescribing today the writing of prescriptions is too important a matter to be left to the whims and fancy of individual doctors.I am, etc.,

\section{Westwood Hospital,
Bradford 6, Yorks. \\ D. A. SPEncer.}

SIR,-In reply to Dr. D. J. Formby (8 March, p. 643), who suggests a possible link between the use of citrated blood and perforation of the gut, we can confirm that our cases were transfused with citrated blood, as we believe is the practice in the majority of British centres. We accept that acidosis may occur in these infants. In our original article (9 November, p. 349) we postulated that hypoxia may play a part in the aetiology, and one knows that hypoxia is usually followed by a fall in $\mathrm{pH}$. If acidosis is the chief factor, however, it is surprising that perforation is not seen more of ten in those conditions known to produce hypoxia and a fall in $p H$ in the newborn, such as respiratory distress syndrome and cyanotic congenital heart disease. In our experience, however, the incidence of perforation of the bowel in these conditions seems to be low.

From the records of this hospital over a period of seven years we have found four more similar cases in addition to those already 